\title{
AS TEORIAS E MÉTODOS DA DIMENSÃO TERRITORIAL DE DESENVOLVIMENTO RURAL NO BRASIL: UMA ABORDAGEM HISTÓRICA NO FINAL DO SÉCULO XX
}

\author{
THE THEORIES AND METHODS OF THE TERRITORIAL DIMENSION OF RURAL DEVELOPMENT \\ IN BRAZIL: A HISTORICAL APPROACH IN THE END OF THE OF 2OTH CENTURY
}

\section{Benedito de Queiroz Alcântara ${ }^{1}$ Ricardo Ângelo Pereira de Lima²}

\footnotetext{
1 Mestre em Direito Ambiental e Políticas Públicas pela UNIFAP; Professor de Direito na FABRAN; Professor de História e Filosofia na Rede Pública Estadual do Amapá; Membro do Grupo de Pesquisa GPCEM-UNIFAP. E-mail: benedito alcantara@hotmail.com

2 Pós-doutor em Geografia, Doutor em Geografia Humana pela UAB/Barcelona, Professor Associado II da UNIFAP, Pesquisador do GAPTA/UFPA. E-mail: ricardo@unifap.br
}

RESUMO: Este artigo busca analisar o desenvolvimento rural no Brasil, as teorias e métodos da dimensão territorial e de desenvolvimento rural de outros países que influenciaram na construção do pensamento brasileiro, buscando compreender a importância da abordagem territorial e os inúmeros obstáculos para o desenvolvimento nacional. Como objetivo, visa apresentar contribuições teórico-metodológicas que foram elaboradas em diversos países, nas décadas de 1970 a 1990, que tiveram acolhida no Brasil, principalmente nas décadas de 1980 e 1990. Como resultados, busca-se contribuir para a reflexão sobre as dinâmicas territoriais que incidem diretamente nas abordagens dos formuladores de políticas públicas relacionadas ao rural brasileiro.

Palavras-chave: Desenvolvimento rural. Território. Ruralidade. Teorias e Métodos territoriais. Desenvolvimento territorial.

ABSTRACT: This article seeks to analyze rural development in Brazil, the theories and methods of the territorial dimension and rural development of other countries that influenced the construction of Brazilian thought, seeking to understand the importance of the territorial approach and the numerous obstacles to national development. As an objective, it aims to present theoretical and methodological contributions that were elaborated in several countries, in the 1970s and 1990s, which were welcomed in Brazil, mainly in the 1980s and 1990s. As a result, we seek to contribute to the reflection on the dynamics that directly affect the approaches of public policy makers related to the Brazilian countryside.

Keywords: Rural development. Territory. Rurality. Territorial Theories and Methods. Territorial development.

Sumário: Introdução - 1 Situando o desenvolvimento rural no Brasil - 2 Situando o debate teórico: dialogando com alguns autores -3 As teorias e métodos da dimensão territorial 4.1. As reflexões teórico-metodológicas em outros países nas décadas de 1970,1980 e 1990-4.2. As reflexões teórico-metodológicas no Brasil nas décadas de 1980 e 1990 - 5. Considerações Finais - Referências

\section{INTRODUÇÃO}

O mundo rural, nas últimas décadas do século XX e no primeiro decênio do atual, passou por mudanças cruciais, principalmente quanto à percepção como os atores sociais, os formuladores de políticas e o mundo acadêmico estão inseridos e atuam nele. Há um instigante debate, que certamente coloca frente a frente referências antagônicas, em um processo de amadurecimento, diante das múltiplas transformações que a sociedade hodierna traz a lume. Múltiplas interrogações que afloram diante da questão em torno do território, da territorialidade, da ruralidade, do desenvolvimento rural e, em específico, do desenvolvimento territorial. 
Como surgiu no cenário brasileiro a incorporação da temática do Desenvolvimento Rural? Quais os furos e igarapés que o pensamento nacional se alimentou? Quais os traços que amalgamou e experimentou na realidade histórica, envolvendo diversos atores e suas múltiplas dimensões? Como acolher a abordagem territorial em um processo dinâmico e de aprendizagem social, que abre um leque de possibilidades para pensar e fazer emergir o desenvolvimento territorial?

O objetivo do presente trabalho, por meio de um recorte temporal, é apresentar e analisar onde brotaram e disseminaram os diversos pensamentos que povoaram a análise dos enfoques e abordagens territoriais, ruralidades e desenvolvimento rural. No pensamento além-fronteiras optou-se iniciar pela década de 1970 e concluir com a década de 1990. Na análise pátria, a escolha recaiu sobre as décadas de 1980 e 1990, retratando com o necessário distanciamento, as diversas transformações que o Brasil atravessou.

Pelo menos quatro indicadores constituem um amálgama que entrelaça os novos modelos e novas propostas frente à temática da ruralidade, da territorialidade e do desenvolvimento rural. A pluralidade de olhares faz-se presente, pois assenta-se a partir de ambientações diferenciadas, mas que não sufocam por inteiro uma leitura de uma tessitura em comum, exigindo a arte de discernir cada posicionamento.

Este artigo certamente não busca exaurir as respostas sobre as perguntas aqui suscitadas, mas tem como finalidade contribuir para a compreensão do que é posto como modelo de desenvolvimento para o Brasil, impactando de imediato todas as mudanças e articulações sócio espaciais e político-institucionais nas diversas escalas de ruralidades e territorialidades

\section{SITUANDO O DESENVOLVIMENTO RURAL NO BRASIL}

Pelo fato do presente trabalho optar pela teoria de base norteadora das reflexões o Desenvolvimento Rural, faz-se relevante introduzir uma breve trajetória que motiva os debates por todo o país, para a compreensão de suas questões e seus elementos constitutivos. Assentou-se a escolha em um recorte temporal, que não seja tão extensivo como a própria história do campo ou da luta pela terra, em termos de populações rurais. A opção foi por um olhar na história recente, a partir da década de 1970.

A intervenção no meio rural brasileiro foi amalgamada pelas ações estatais e pelos organismos internacionais, em uma época remota, onde a ênfase era nas intervenções de caráter compensatório, preenchendo lacunas no pequeno fôlego dos agricultores em acompanhar a chamada modernização tecnológica que a revolução verde preconizava. Os exemplos foram explicitados na leva colonizadora na Amazônia e nas frentes de trabalho de combate à seca na região nordestina. Eram as Políticas de Desenvolvimento Rural Integrado (PDRI), conforme relato sucinto em artigo-resenha de Schneider (2010).

Já em plena década de 1990, irrompe uma extraordinária mudança de compreensão sobre o desenvolvimento rural, com novas abordagens, divergindo qualitativamente das bases assentadas na década de 1970. E isto vale tanto para o campo das políticas públicas como para o campo das discussões acadêmicas. Entre as duas cronologias citadas, tem-se a década de 1980, que traz como herança a grave crise econômica, germinada na década anterior, sendo considerada por parcelas significativas da opinião pública como a década perdida. A conscientização das principais forças políticas do país canalizava para um esforço conjunto em estabilizar a macroeconomia, ao mesmo tempo que passava a vigorar diversas regulamentações advindas da Constituição da República Federativa do Brasil (CRFB), de 1988.

No âmbito das forças sociais, faz-se necessário apontar que as organizações e movimentos foram duramente reprimidos durante a ditadura militar, quando eram pautados por uma agenda reivindicativa e contestatória. Já na década de 1990, a agenda passa a ser proativa e propositiva, readquirindo e ampliando as formas de expressão. Um outro aspecto emergente ao debate, refere-se à questão da noção de sustentabilidade e meio ambiente, como desdobramento da realização da Conferência da Organização das Nações Unidas, na cidade do Rio de Janeiro em 1992.

Assim posto, a temática do Desenvolvimento Rural vai incorporando múltiplas dimensões e diversas adjetivações, com seus elementos positivos e ao mesmo tempo limitantes e até contraditórios. Porém, não há como negar que o Desenvolvimento Rural ganhou um amplo cenário de discussões, angariando uma 
legitimidade singular no tempo presente. Assim, questiona-se: Quais foram os fatores que incidiram e favoreceram a percepção de uma nova visão sobre este assunto?

Quatro fatores afloram para a leitura em resposta a este questionamento: O primeiro fator relacionase com "a trajetória das discussões em torno da agricultura familiar e de seu potencial como modelo social, econômico e produtivo para a sociedade brasileira” (SCHNEIDER, 2010, p.515). É na primeira metade da década de 1990 que a noção agricultura familiar ganha um status de categoria política, assimilada tanto pelos meios acadêmicos como pelos formuladores de políticas, em um processo intenso de legitimidade. Sem olvidar-se que há uma trajetória de lutas sociais de resistência e de interpelações por políticas para o setor, conforme estudo de Gehlen (2004).

O debate em torno do Desenvolvimento Rural no Brasil é alicerçado por um segundo fator, que diz respeito à crescente influência da ação estatal no meio rural, em formas de políticas para a agricultura familiar, tanto como ações ligadas à reforma agrária, quanto a ações ligadas à segurança alimentar. O Estado brasileiro, de forma crescente, passa a legitimar toda uma agenda reivindicatória advinda dos movimentos sociais do campo.

Um terceiro fator que incide no fortalecimento sobre Desenvolvimento Rural no Brasil, advém das mudanças no âmbito político e ideológico, com suas duplas e dúbias significações. De um lado, encontramse alguns setores das elites agrárias totalmente refratárias a qualquer mudança, em especial na adesão de políticas sociais e de caráter compensatório, mas que historicamente foram levadas a mudar de posicionamento, inclusive na questão da reforma agrária, item nevrálgico e nunca posto em qualquer mesa de negociação, por parte das elites agrárias.

De outro lado, a mudança foi ocorrendo na construção de uma argumentação que buscava desnudar as diferenças fundamentais no interior do mundo dos produtores rurais, para que ficasse bem nítida para toda a sociedade brasileira que o campo possuía uma produção para o consumo local (mercado interno) e uma outra produção voltada para a exportação. Tal dualismo gerou uma ácida e nem tão pouca delicada disputa política e ideológica. Foi um verdadeiro arrastão de debates, que seduziu mentes e corações em todos os setores envolvidos, como as organizações sociais, o mundo acadêmico, além dos setores formuladores de políticas. A dubiedade da questão foi erguer no patamar de opositores a alternativa do desenvolvimento rural frente à noção da agricultura para o agronegócio ${ }^{1}$.

O quarto fator que alimenta as discussões sobre o Desenvolvimento Rural, recai na temática da sustentabilidade ambiental, cujo cenário de debates extrapola em muito as fronteiras do rural e vem bem antes da retomada das reflexões em torno do Desenvolvimento Rural. Aqui afloram duas situações: primeiramente, a avalanche de críticas ao modelo agrícola da revolução verde, agregando simultaneamente a questão ambiental a modelos alternativos na área técnico-produtiva; e, uma segunda vertente, uma outra situação em simbiose de ideias e ações, no referente ao crescente interesse acadêmico em construir a noção de sustentabilidade em referencial teórico e modelo de desenvolvimento. Esses dois movimentos alimentam sobremaneira o debate sobre o Desenvolvimento Rural, indo até o ponto de aparecer em cena o adjetivo sustentável, tamanha a força aglutinadora das situações históricas por quais passava o país.

\section{SITUANDO O DEBATE TEÓRICO: DIALOGANDO COM ALGUNS AUTO- RES}

Com a breve visão histórica posta, fornecendo os diversos contextos e fatores que levaram ao debate corrente sobre o tema do Desenvolvimento Rural no Brasil, novas interpelações gravitam no horizonte: como os formuladores das políticas elaboram sua agenda? Qual a origem da inspiração do Estado e como são formulados os programas e as propostas que abastecem e potencializam as discussões sobre o

\footnotetext{
1 Schneider(2010) cita um exemplo que percorre os corredores dos debates e simboliza a situação, que é a existência de dois Ministérios do Governo Federal que possuem ação direta na área rural: o Ministério da Agricultura, Pecuária e Abastecimento(MAPA) e o Ministério do Desenvolvimento Agrário(MDA).
} 
Desenvolvimento Rural?

Seguindo a contribuição de Schneider (2010), há duas possibilidades de encontrar as respostas para tais interpelações: a primeira hipótese é acreditar que a agenda do Estado apenas reflete a demanda social, que com sua habitual pressão de seus atores e instituições, cercam a tecnocracia estatal em busca de viabilidades de suas demandas. Em outra hipótese, considera-se que os debates e os temas do Desenvolvimento Rural sejam frutos da efetiva elaboração acadêmica que se debruçou sobre a temática, alimentados em muito por mediadores e organizações que interagem com as implementações das políticas estatais para o mundo rural. Pode-se interpelar: afinal, quem formulou a agenda de atuação estatal, ou, influenciou de mais ou de menos? Os habitantes do mundo rural ou os habitantes do mundo acadêmico e seus mediadores?

Constata-se que, a agenda aglutinadora das Políticas de Desenvolvimento Rural do Estado nos anos recentes, foi densamente povoada pelos pensamentos e propostas absorvidas pelos formuladores de políticas junto aos acadêmicos e mediadores, conforme uma eficiente influência e incisiva articulação. Em uma tentativa de construir uma visão de conjunto, colhe-se algumas convergências, navegando pelas reflexões postas em debate. Entre elas, a concordância quanto à perda de sentido quando se reduz o rural às atividades agropecuárias. Outra, é referente à dimensão multidimensional da sustentabilidade do desenvolvimento e o papel da agricultura familiar com suas inúmeras inserções na economia. E, cada vez mais aceito pelas abordagens, que o foco das ações do Desenvolvimento Rural deve ser o combate à pobreza e às vulnerabilidades das populações rurais.

Como referência para sustentar a reflexão sobre o tema do Desenvolvimento Rural, necessariamente buscou-se o apoio relevante e mais do que necessário de diversos pesquisadores, sem a ousadia de querer esgotar por inteiro uma rica e crescente contribuição acadêmica que hoje se oferece no cenário brasileiro. Aglutinando em quatro tendências de percepção, Schneider (2010) busca caracterizar as diversas abordagens:

Uma primeira abordagem traz as valiosas reflexões de Veiga (2002) e Abramovay (2000 e 2003), com longas trajetórias de pesquisas e contribuições, em uma perspectiva multidisciplinar, com ênfase na economia, na ecologia e na sociologia econômica, angariando um séquito que dá amplitude aos seus pensamentos, tanto na academia, como nas instituições dos movimentos sociais e, também, em diversas instâncias do governo. Em caminhos comuns, os dois pesquisadores, valorizam a agricultura familiar e seu potencial dinamizador econômico local; a capacidade inovadora e empreendedora dos agricultores familiares, levandoos a uma diversificação social e produtiva dos territórios rurais onde se ubicam e as interações com as instituições locais.

Veiga (2002), problematiza com ênfase a natureza territorial do próprio espaço rural, afirmando que aquilo que chamamos de rural brasileiro é muito mais abrangente que os números censitários oficiais. Enquanto Abramovay (2000 e 2003), traz a reflexão sobre o papel do capital social, inspirado nos estudos de Putnam (1993), discorrendo sobre os fatores que geram cooperação, reciprocidade e solidariedade, como elementos fundantes que inspiram as economias de proximidades, superando os conflitos locais.

Para Abramovay (2003), carreiam duas correntes atuais de pensamento sobre o Desenvolvimento Rural: uma vertente que dá ênfase à dimensão territorial do desenvolvimento (que se articulam em redes, com o intuito de enriquecer o tecido social de determinada localidade); outra vertente que se debruça sobre o capital social (como instrumento para a solução dos dilemas da ação coletiva, expressão do ethos de uma certa sociedade). O teórico observa que há uma clara convergência entre os pressupostos que alicerçam a noção de capital social e as premissas formadoras do desenvolvimento territorial.

Cabe assinalar outro consenso nos dois autores, quando se referem à atuação das instituições no meio rural. Para Veiga (2002), o Estado está em um mesmo passo de inserção com as demais instituições (empresas públicas, consórcios intermunicipais, agências e universidades). Em Abramovay (2000), o seu olhar recai sobre as organizações dos agricultores, com suas formas de cooperação, interagindo com as regras e normas presentes nos territórios. Para ambos os pensadores, fica destacada a importância das instituições em gestar um ambiente institucional favorável de governança, contribuindo sobremaneira para a redução dos riscos e incertezas.

Uma segunda tendência de abordagem versará sobre o novo rural brasileiro, enquanto atividades 
não-agrícolas e demais políticas compensatórias, fruto de um arcabouço analítico e conceitual advindo das reflexões efetivadas pelo Projeto Rurbano ${ }^{2}$ que reuniu um grupo de pesquisadores liderados por José Graziano da Silva, onde demonstraram que o meio rural do final do século XX, já não podia ser tão somente assinalado como agrícola.

Em linhas gerais, o novo rural deixa de ser sinônimo de atraso, por ter uma nova conformação econômica e demográfica, em uma crescente redução das diferenças entre o urbano e o rural, onde a agricultura é apenas uma das atividades. De um lado, apresentam-se três grupos de atividades: o agronegócio e suas agroindústrias; um conjunto de atividades não-agrícolas que incidem na questão da moradia, do lazer e prestação de serviços; e, um último grupo, atividades agropecuárias direcionadas a nichos de mercado. São as famílias pluriativas, porque combinam atividades agrícolas e não-agrícolas e porque também promovem a integração intersetorial e interespacial.

Por outro lado, compondo também o mesmo cenário, em oposição à faceta moderna, apresenta-se o lado atrasado, com seu quadro de miséria e vulnerabilidade social, com seus excluídos e desorganizados, onde incidirá as políticas compensatórias. Esta tendência propugna a convergência de políticas sociais e compensatórias para o rural atrasado e políticas para o novo rural, com atividades de emprego e renda em setores não-agrícolas.

Uma terceira tendência de estudos debruça-se sobre a força da tradição e os limites históricos e sociais ao Desenvolvimento Rural. Parte-se de estudos sobre o clientelismo, o patriarcalismo e outros comportamentos sociais e políticos, que apontam, segundo diversos sociólogos e cientistas políticos, mecanismos de dominação cultural e social que se tornam instrumentos legitimadores de poder e de privilégios de elites locais, exigindo, portanto, processos radicais de democratização, na perspectiva de libertação de indivíduos e grupos sociais da tutela dos vários mediadores (Estado, Igreja, Partido Político, Movimento Social).

Os autores mais destacados em tal perspectiva de reflexão são Martins (1981) e Navarro (2001) que propugnam que "os processos de desenvolvimento podem e devem contribuir, efetivamente, para estimular a 'emancipação social', criar mecanismos de responsabilização (accountability) e, desse modo, promover a democratização da sociedade” (SCHNEIDER, 2010, p.523).

Para Martins (1981 apud SCHNEIDER, 2010, p.523), “a história do Brasil está repleta de exemplos de práticas cuja proposta de 'ajudar os outros' acaba criando formas de dominação e controle dos outros". São as contradições da sociedade brasileira, que de um lado chega a uma formidável modernização, ao mesmo tempo que, por outro lado, exprime diversas formas de controle e dominação. Em outras palavras, há um processo conservador de modernização.

Para Navarro (2001), os atores sociais rurais apresentam-se demasiadamente frágeis, com suas bases instáveis e sempre subordinadas a elementos externos, incapazes, portanto, de promoverem e estimularem uma real democratização da sociedade. Para este autor, em termos de um processo de desenvolvimento local, há uma premissa falsa no Brasil, que sustenta que os atores sociais locais estariam aptos a exercerem atividades locais.

O quarto grupamento de abordagem, tem como enfoque o agronegócio e as cadeias agroalimentares. Busca-se refletir sobre a inserção dos pequenos agricultores e seus aspectos sociais de tal processo. Ou seja, compreender como os pequenos produtores e suas organizações fazem frente aos desafios postos pela operatividade capitalista no campo. É um olhar sobre um tipo de agricultura familiar mais inserida no modus vivendi do capitalismo, que acessam mercados e tecnologias, com localização em regiões mais dinâmicas das economias rurais.

Há uma gradual superação da noção de cadeia de produção, para sobressair a noção de redes, sendo esta, mais adequada para interagir com os aspectos sociais e técnicos da produção. De acordo com Wilkinson (2003), tal ideia apresenta-se como útil e conveniente para suprir os aspectos sociais e técnicos da produção. Vem à tona a grande capacidade de inovação e de aprendizagem coletiva, com ajustes constantes no processo

2 O Projeto Rurbano mobilizou mais de quatro dezenas de pesquisadores, de onze estados brasileiros, de vinte instituições, gerando mais de vinte subprojetos de pesquisas, desde o ano de 1996 (GRAZIANO DA SILVA, 1996). 
de produção. Com toda esta potencialidade, não se pode olvidar, também, de que há riscos e limitações.

Outros autores, também interessantes e atuais, trazem novos olhares e ampliam mais e mais o debruçar-se sobre a temática do Desenvolvimento Rural, contribuindo, sem dúvida, para uma legitimidade em torno da discussão. Por exemplo, quando é posta a questão sobre a diluição de fronteiras, na perspectiva de um possível fim do rural, o aporte de Wanderley (2000) é muito pertinente, quando explicita que os processos recentes de transformações não indicam necessariamente o fim do rural. Ao contrário, há o surgimento de uma nova ruralidade (WANDERLEY, 2000).

Outro pensamento, de Carneiro (1998), reconhece as mudanças no mundo rural, que não significa a perda de identidade, pela diluição das fronteiras. Há uma âncora territorial que interage e mantém uma identidade. Para a pensadora, o mais importante não é localizar por onde passa a fronteira entre o rural e o urbano, e sim adentrar nos significados das práticas sociais dos diversos agentes que vivenciam estes espaços. O contexto mais amplo, certamente, são os diferentes processos de transformação que hoje incidem na sociedade ocidental contemporânea e a realidade brasileira não poderia estar imune a tal empreitada histórica.

Não obstante às diferentes visões em seus aportes teóricos sobre o Desenvolvimento Rural, nos autores que aqui se apresentaram em diálogo, fica sobejamente demonstrado a atual importância do tema, que abre cenários desafiadores na realidade brasileira, seja para o papel do Estado e suas relações com o meio rural, seja para os mediadores e estudiosos, seja para os próprios atores sociais do campo e suas organizações, em um processo de interação e pressão, de polarização e intervenção, que urgem em definir sempre mais uma agenda temática sobre o Desenvolvimento Rural no Brasil. O caminho está posto, assim como as várias maneiras de caminhar.

\section{TEORIAS E METODOS DA DIMENSÃO TERRITORIAL}

O caminho percorrido nos itens anteriores desemboca necessariamente no entendimento sobre a dimensão territorial, em suas visões e concepções teóricas e metodológicas que a abordagem territorial vem marcando presença, sempre em um quadro de contínua mudança. Há um processo de atualização e de alteração permanente, tanto no enfoque acadêmico e analítico, por força de sua própria dinâmica, como também, no campo das relações de poder e implementação das políticas públicas, além do domínio das práticas sociais, em sua busca de novos referenciais que legitimam suas inserções no tecido social.

No âmbito teórico e metodológico, a perspectiva territorial é alimentada sobremaneira pelas discussões sobre a Ruralidade, a Territorialidade e o Desenvolvimento, com um longo alcance e amplitude, expondo-se a muitas críticas e restrições, mas como já apresentado anteriormente, trazendo toda uma riqueza de reflexões que apontam luminares para a compreensão do tema central em debate. Importa ressaltar que cada um dos três domínios, a partir de suas diferentes visões e percepções, incide em uma abordagem territorial.

Qual seria, portanto, a renovação teórico-metodológica a partir da abordagem territorial? Além dos diversos autores que foram trazidos para a presente reflexão, lança-se mão da riquíssima contribuição do pensamento de Saquet (2004, 2010, 2011), que faz uma viagem pelas abordagens e concepções de território.

Para Saquet (2010) dois autores vão influenciar sobremodo os estudos territoriais em diversos países e no Brasil: Francesco Indovina e Donatella Calabi. Esses autores, segundo Saquet (2010, p.70) indicam os estudos de "uma abordagem essencialmente econômica e material da organização social do território". Assim, o território é um produto socialmente organizado, em um primeiro plano, e também condição para a valorização do capital, em um segundo plano. Na mesma linha de abordagem dos dois autores acima, apresenta-se a abordagem de Alberto Magnaghi, onde o território "significa fluxos, normas, conflitos, influência e dominação; gestão político-econômica; redes intra e extra locais; valorização do capital e relações de poder [...]" (SAQUET, 2010, p. 71-72).

Em distinta leitura das anteriormente são apresentadas no pensamento de Raffestin (1993), acolhese um pensar que vem da chamada escola anglo-saxônica, como outra vertente teórico-metodológica, que vem desde os anos 1970, debruçada sobre os significados do espaço, que é a perspectiva de Robert Sack, de 
formação não marxista. Este autor britânico, compreende o território "como área controlada e delimitada por alguma autoridade, como resultado das estratégias de influência que ocorrem individualmente ou através de grupos sociais" (SAQUET, 2010, p. 84).

Os estudos e reflexões em torno da temática territorial elevam-se consideravelmente a partir dos anos 1990, tanto na geografia como nas ciências sociais, no Brasil e em outros países. Saquet (2010, p. 97) afirma que há diversos estudos com pouca consistência teórico-metodológica, ou que realizam uma abordagem em um campo específico (política, econômica, cultural), mas que, ao mesmo tempo, adentram a cena acadêmica obras de magnitude epistemológica. Na França, Saquet (2010), descortina os avanços nas pesquisas de G. Deleuze e F. Guattari, que em uma profunda reflexão filosófica, canalizam suas análises em favor da reterritorialização diante da desterritorialização. O Território está umbilicalmente ligado ao chão, como enraizamento, mas também, como transformação e separação.

Após um périplo pela produção acadêmica em outros países, faz-se mister incidir a trajetória pela produção brasileira, que tanto recebeu influência do que ocorria externamente, como também, influenciou com uma produção intelectual pátria que foi além de suas fronteiras. Para a década de 1980, indica-se os seguintes autores e suas respectivas reflexões:

Goldenstein e Seabra (1980), em estudo pioneiro no começo da década de 1980, utilizam o conceito de território, partindo do processo de divisão social e territorial do trabalho, encaixado em uma dimensão espacial, como áreas que se combinam e se relacionam, em interação com os conceitos de região, regionalização e território. Becker (1983), por outro lado, argumenta no conceito de território involucrada por seu uso político, onde o Estado-nação acaba escondendo os conflitos existentes nas múltiplas relações de poder. A autora reforça o pensamento de Raffestin (1993) no Brasil, onde expõe as dimensões sociais da economia e da política territorial, com seus limites e suas malhas (SAQUET, 2010).

Santos (1988), finalmente, apresentará um salto qualificativo de ênfase na temática, com suas reflexões a partir de 1988, em torno do espaço geográfico, em sua abordagem materialista dialética, mas reconhecendo a política, a cultura, a natureza e o espaço na configuração territorial. Santos (1988) apresenta um esforço teórico-metodológico em superar a velha dicotomia entre geografia física e a geografia humana, quando reconhece elementos naturais e elementos sociais no território. O território ainda corresponde ao Estado-nação, mas também significa relações sociais, fluxos, como "produto histórico modelado por cada sociedade, com uma certa configuração" (SAQUET, 2010, p.91).

Já no início da década de 1990, precisamente no biênio 1992-93, são realizados na cidade de São Paulo, dois seminários internacionais, (O novo mapa do mundo e Território: globalização e fragmentação). Ao mesmo tempo, é traduzido para o português, o livro de Claude Raffestin, Por uma geografia do poder. Há uma conjugação de fatores, tanto internos como externos, que geram um ambiente propício para o surgimento de diversos estudos territoriais.

Para Saquet (2010), tais reflexões podem ser aglutinadas em cinco perspectivas e concepções: a) o destaque para os aspectos econômicos e políticos do território e da territorialidade, com os estudos de Raffestin e outros; b) o destaque para as dimensões da cultura e da política, pelo pensamento da dupla Deleuze e Guattari; c) o destaque na geopolítica, com as reflexões de Gottmann e Sack; d) o destaque em torno dos fenômenos e processos de desenvolvimento territorial, inferidos por Bagnasco, Becattini, Dematteis e outros e; e) o destaque da configuração territorial, dos fixos, fluxos e do território usado, com a compreensão feita por Milton Santos.

Com uma plêiade de pensadores e centros acadêmicos debruçados sobre a temática, urge apontar algumas referências que agregam pertinência e relevância a esta reflexão que ora se discorre. Para tanto, foram indicados como norteadores três pensadores que ilustram como no Brasil da década de 1990, as abordagens teórico-metodológicas estavam em plena efervescência.

Inicia-se com o teórico Milton Santos, em uma abordagem materialista, centrada no conceito de espaço geográfico. Sua argumentação profundamente epistemológica, percorre uma apreensão de território como espaço geograficamente organizado, ou território usado, em uma configuração com interferências humanas, com limites e com a natureza. É no território que estão as ações e os objetos. O geógrafo, também, 
aponta a atuação do dinheiro e das técnicas na reorganização do território, onde as forças econômicas e políticas (Estado-Nação) usam o território submisso às orientações do capital. “O território é usado como recurso pelos atores hegemônicos e como abrigo pelos hegemonizados” (Saquet, 2010, p.124).

Haesbaert (2006) é o segundo pensador escolhido para representar a corrente brasileira que adensava suas reflexões teórico-metodológicas em torno da temática territorial, a partir dos anos 1990. Para este pesquisador, há processos de dominação e apropriação na construção do território, em busca da conciliação de aspectos objetivos e subjetivos. Verifica-se o domínio social, econômico, político e cultural do espaço e, mais tarde, incorpora também a dimensão natural, como base e materialidade do espaço.

Para Haesbaert (2006), são as relações de força (relações de poder) que condicionam e constituem o território. Também, o pensador vai contribuir com a temática em tela, ao verificar que a produção do espaço envolve tanto a desterritorialização como a reterritorialização, isto é, o território representa ao mesmo tempo coesão e identidade, como apropriação e ordenamento político.

Finalmente, completando a tríade de estudiosos, apresenta-se a reflexão de Saquet, que desde os anos de 1993-1994, vem estabelecendo, inicialmente, algumas ideias, como o conceito de produção social do espaço. Já a partir dos anos 2000, adentra em uma abordagem (i)material do território, com a noção de espaço construído socialmente, tanto de forma objetiva como de forma subjetiva. Como desdobramento de suas argumentações teórico-metodológicas, verifica-se a ligação indissociável entre espaço e território, onde o processo de territorialização é um movimento historicamente determinado, que gesta tanto as desterritorialidades como as reterritorialidades. "O território é compreendido, antes de qualquer coisa, como um espaço de organização e luta, de vivência da cidadania e do caráter participativo da gestão do diferente e do desigual" (SAQUET, 2010, p.129).

Para o pesquisador, a abordagem territorial é um esforço de compreensão de um vasto universo de processos, redes, rearranjos e contradições, de heterogeneidade, de tempos e territórios, tão somente um jeito de contemplação da (i)materialidade do mundo da vida (SAQUET, 2010). Assim, observa-se uma robusta trajetória na reflexão teórico-metodológica que aborda a temática territorial, que vai se avolumando gradativamente, tanto no cenário acadêmico de outros países como no cenário intelectual brasileiro, pleno de atualidade e relevância, perpassando diversos grupos de estudos, departamentos, universidades, ao mesmo tempo estimulados e questionados por uma inserção de políticas públicas que vão se efetivando em todo o país, tendo como problemática o desenvolvimento rural no recorte territorial.

\section{CONSIDERAÇÕES FINAIS}

Com este trabalho, intentou-se apresentar a trajetória histórica da temática do desenvolvimento rural, nas últimas três décadas do século passado, em alguns países e no Brasil, ocupando progressivamente um palco catalisador de reflexões, com suas variações e diferenciações, que apontam luzes para o cenário presente, tão recheado de sombras e incertezas.

Uma primeira observação versa em torno do chamado novo rural brasileiro, que extrapola em muito as atividades agrícolas, acentuadamente desde o final do século passado, agregando atividades não-agrícolas e demais políticas compensatórias. Uma segunda tendência de estudos debruça-se sobre a força da tradição onde mecanismos de dominação cultural e social que se tornam instrumentos legitimadores de poder e de privilégios de elites locais, sendo necessários processos radicais de democratização, na perspectiva de libertação de indivíduos e grupos sociais da tutela dos vários mediadores (Estado, Igreja, Partido Político, Movimento Social).

A terceira observação aborda o agronegócio e as cadeias agroalimentares, onde se busca compreender como os pequenos produtores e suas organizações fazem frente aos desafios postos pela imperatividade capitalista no campo, para desta maneira entender a sua inserção no processo de construção dos novos territórios rurais.

Em suma, apresentou-se uma trajetória na reflexão teórico-metodológica, em sua abordagem territorial, que vai se avolumando gradativamente, tanto no cenário acadêmico de outros países como no cenário 
intelectual brasileiro, perpassando e alimentando diversos grupos de estudos, departamentos e universidades e, ao mesmo tempo estimulados e questionados por uma inserção de políticas públicas que vão se efetivando em todo o país, que faz com que o assunto em questão, impacta por ser pleno de atualidade e relevância tendo como problemática o desenvolvimento rural no recorte territorial.

\section{REFERÊNCIAS}

ABRAMOVAY, Ricardo. O capital social dos territórios: repensando o desenvolvimento rural. Revista Economia Aplicada-n ${ }^{\circ}$ 2, vol. IV: 379-397, abril/junho, 2000.

. O futuro das regiões rurais. Porto Alegre: Ed. UFRGS, 2003.

BECKER, Bertha K. O uso político do território: questões a partir de uma visão do Terceiro Mundo. In: BECKER, B. K.; COSTA, R.; SILVEIRA, C. Abordagens políticas da espacialidade. Rio de Janeiro: UFRJ, 1983.

. Constituição (1988). Constituição da República Federativa do Brasil. São Paulo: Saraiva, 2016. CARNEIRO, Maria José. Camponeses, Agricultores e Pluriatividade. Rio de Janeiro: Contra-Capa, 1998.

HAESBAERT, Rogério. O mito da desterritorialização: do "fim dos territórios" à multiterritorialidade. 2 ed. Rio de Janeiro: Bertrand Brasil, 2006.

GEHLEN, Ivaldo. Políticas públicas e desenvolvimento social rural. São Paulo, v. 18, n. 2, jun. 2004.

GOLDENSTEIN, L.; SEABRA, M. Divisão territorial do trabalho e nova regionalização. Revista do Departamento de Geografia, São Paulo (1): 21- 47, 1980.

GRAZIANO DA SILVA, José. A nova dinâmica da agricultura brasileira. Campinas: Unicamp-Instituto de Economia, 1996. 217p.

MARTINS, J.S. Os camponeses e a política. As lutas sociais no campo e seu lugar no processo político, Rio de Janeiro: Vozes, $1^{\text {a }}$ Edição, 1981.

NAVARRO, Zander. Desenvolvimento rural no Brasil: os limites do passado e os caminhos do futuro. Estud. av., São Paulo, v. 15, n. 43, dez. 2001.

PUTNAM, Robert. Comunidade e democracia. A experiência da Itália moderna. Rio de Janeiro. Fundação Getúlio Vargas, tradução de Making Democracy Work: Civic Traditions in Modern Italy, 1993.

RAFFESTIN, Claude. Por uma geografia do poder. São Paulo: Ática, 1993.

SANTOS, M. Metamorfoses do espaço habitado. São Paulo: Hucitec, 1988.

SAQUET, Marcos Aurélio. Abordagens e concepções de território. 2ed., São Paulo: Expressão Popular, 2010 .

- Marcos A. O território: diferentes interpretações na literatura italiana. In: RIBAS, Alexandre D. et $\overline{a l}$ (orgs). Território e desenvolvimento: diferentes abordagens. 2. ed. Francisco Beltrão: Unioeste, 2004. p. 121-147.

. Por uma geografia das territorialidades e das temporalidades: uma concepção multidimensional voltada para a cooperação e para o desenvolvimento territorial.1 ed., São Paulo: Outras expressões, 2011.

SCHNEIDER, Sergio. Situando o desenvolvimento rural no Brasil: o contexto e as questões em debate. Revista de Economia Política, vol.30, n3 (119), pp. 511-531, julho-setembro/2010.

VEIGA, José Eli da. Cidades imaginárias: o Brasil é menos urbano do que se calcula. Campinas: Editora Autores Associados, 2002.

WANDERLEY, Maria de Nazareth Baudel. A valorização da agricultura familiar e a reivindicação da ruralidade no Brasil. Curitiba: Editora da UFPR, 2000.

WILKINSON, J. A agricultura familiar ante o novo padrão de competitividade do sistema alimentar na América Latina. Estudos Sociedade e Agricultura, n.21,2003. 